\title{
Design and Implementation of Information System of 3D City of Geotechnical Engineering
}

\author{
Luo Qiong \\ SICHUAN COLLEGE OF ARCHITECTURAL TECHNOLOGY \\ 346591653@163.com
}

Keywords: City Geotechnical Investigation, Database, GIS

\begin{abstract}
To meet the demand for the geotechnical information system management, this paper has put forward a plan to develop the management information system by using GIS and commercial database management technology. It has also described and analyzed the development of the function modules of the system and designed its module structure architecture for further development of the system. The GIS and database technology may be applied in managing, analyzing and evaluating the sea-volume geotechnical information data and help realize information sharing and provide policy-making support for the city planning, construction and management.
\end{abstract}

\section{Introduction}

Since the founding of new China, our country has been in engineering exploration drilling often based on drilling a peephole view combined with engineering and technical personnel of experience to speculate. The breadth and precision depends on the exploration site density and depth to get exploration results. Skeleton of the visualization system is seen as Fig. 1. Due to the nature of the condition of the myriads of changes, rely on this means of access to information are often limited [1]. Some preliminary work seems to be blind and disorderly. Through a large number of engineering practices, we realize that in order to further improve the engineering quality and efficiency, especially when the need to make a macro decision a lot of data related to geographic locations is essential [2]. The best way to solve the above problems is to establish a geographic information system.

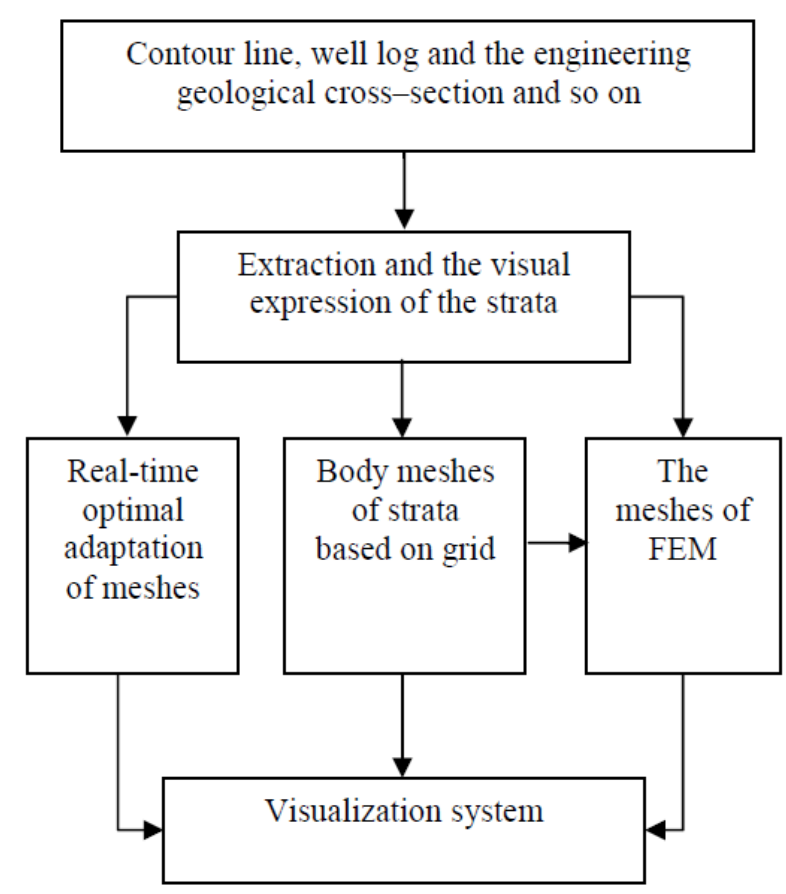

Fig. 1. Skeleton of the visualization system 


\section{City Geographic Information System}

At present, domestic and international integration city needs digital city geographic information system development. UGIS is a comprehensive technology planning, measurement, geography, information, management, society, computer science and application objects of knowledge as a whole [3]. UGIS application has become more mature technology in developed countries, Japan, Canada, Australia America and Germany, having made considerable social and economic benefits [4]. Well logs and virtual well logs are seen as Fig. 2. UGIS technology from the field of macro management environment, resources and gradually to the micro management of engineering and industrial network and production management direction, combined with the economic development more closely. The UGIS project involves a wide range, a large amount of information and high precision [5]. The basic requirements of data integrity, long construction period, the successful construction, social and economic benefits are enormous.

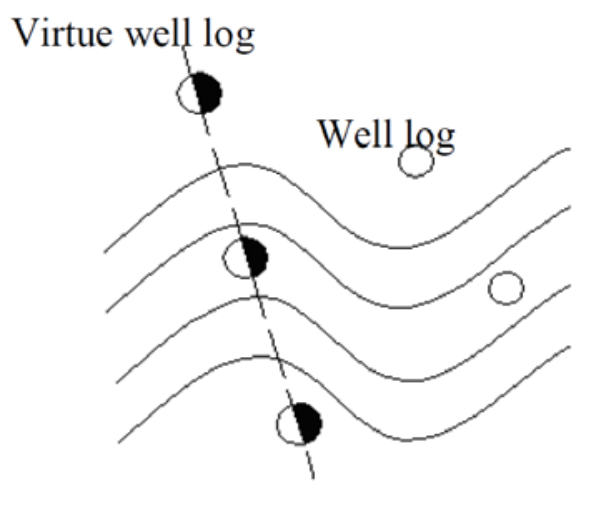

Geological cross-section

Fig. 2. Well logs and virtual well logs

Management information system is an important part of UGIS. Along with the development of computer science, computer is used more and more widely in city planning management. Especially as the development and application of geographic information system is an important branch of the information technology, creating favorable conditions for engineering construction management information system. Management information system is based on the geotechnical engineering investigation results information as the basis in the computer system. A node of a quadtree structure is seen as Fig. 3. The computer database is based on the city basic geographic information system and form and information processing system.

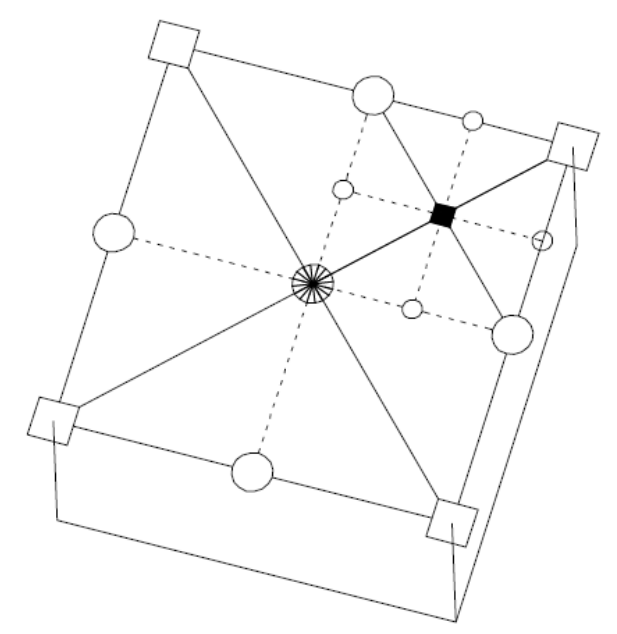

Fig. 3. A node of a quadtree structure 


\section{Design System Development Program}

The development goal of the system should be integrated to establish a geographic information system and management information system and information management system. To meet the comprehensive management of prospecting information data of geotechnical engineering adapt to the social public widely query. Therefore, the characteristics of system development require a combination of GIS. MIS, Through the COM -DCOM graphics data, business information and technical communication and collaboration platform are integrated in one, with strong flexibility and integration. The elevation of a node by the DEM grid is seen as Fig. 4. Management information systems must also be information collection, database management and spatial data analysis as a whole. Fully meeting the various needs of engineering investigation information management of user can provide a comprehensive, standardized platform for managers and engineers.

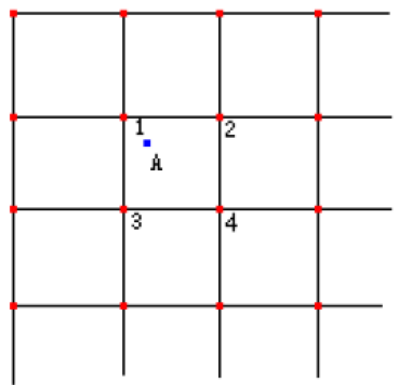

Fig. 4. The elevation of a node by the DEM grid

The general design scheme of the system can be divided into database management module, query module, statistics analysis module, thematic map making module and the output of the system function. Graphic data input, topographic maps and image maps, such as background image can be a variety of input methods, such as the keyboard, mouse, digital instrument manual collection and file data format conversion. The exploded view of three-dimensional mesh model is seen as Fig. 5. Attribute data input requirements based on the database system of large database platform. The basic function is of the database operation, including increase, delete and modify the data record and the rationality of the data check.

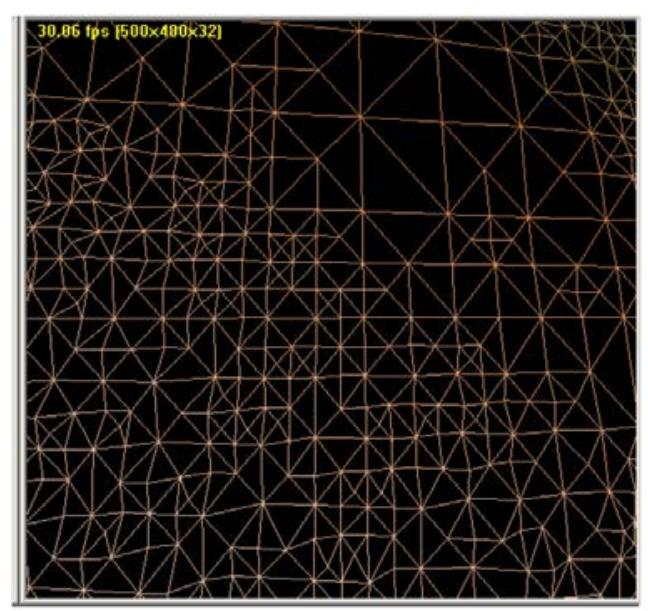

Fig. 5. The exploded view of three-dimensional mesh model

This module is an information management system for the user development. According to the different information carrier it can be divided into map browsing query and data query sub module 2 . Map browsing query sub module is the use of electronic map as the background of the project distribution map query. Data query as a supplement to the map browsing query is a database oriented query module according to different application requirements according to the different way of query. 


\section{Application of City for Investigation of Geotechnical Engineering Information Management System}

In the construction of the aircraft design and Research Institute of geotechnical engineering investigation in the management information system, using the MAPGIS software platform. Preliminary implementation survey information management data in geotechnical engineering improve the modernization level of data management timely accurately provide information and services related to city planning, city construction, decision making and engineering consulting. The system provides the information management based on GIS. The roaming function can be arbitrarily designated regional engineering geological condition and related information query.

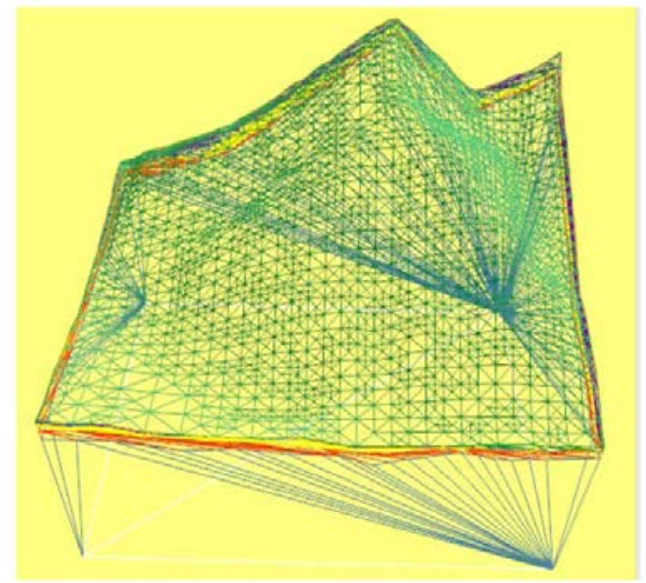

Fig. 6. Real-time optimal adaptation of meshes

At the same time, you can enter the project number, project name, project location and other fields in the local information fast query specified engineering geological data. It and can directly output the single holes histogram or geological profile.

\section{Conclusions}

With the rapid development of information technology, the focus of single simple data information is not of concern. Temporal data information more and more people are keen to multi-level, multi-functional comprehensive analysis ability. This system as the input, storage, retrieval, analysis and display of various engineering geological features of information related to the geographical location of the computer aided decision system from the macro and micro allows experts to engineering geological information more comprehensive analysis, multiprocessing, past single retrieval methods heap old model of data management changed.

\section{References}

[1] B.X. Peng, City investigation nearly ten years of development tendency discussion, City Survey, 13(1), 2000, 5-7.

[2] S.Z. Zhang, Info-Geot ECH management information system development program, Geological Science and Technology Information, 11(3), 2001, 105-109.

[3] W.P. Peng, Mode of city development of engineering geological information system, City Survey, 3(4), 1999, 45-48.

[4] R.Q. Huang, H. Deng and X.Q. Xiang, Application in the geotechnical engineering information technology, Geotechnical Engineering, 4(6), 2001, 50-55.

[5] C.X. Wang and S.W. Bai, Application of 3D strata information system in geotechnical engineering, Rock and Soil Mechanics, 25(4), 2003, 614-617. 